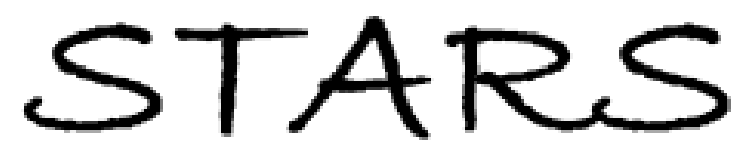

University of Central Florida

STARS

$1-1-2003$

\title{
Microscale resin-bonded permanent magnets for magnetic micro- electro-mechanical systems applications
}

Hyoung J. Cho

University of Central Florida

Chong $\mathrm{H}$. Ahn

Find similar works at: https://stars.library.ucf.edu/facultybib2000

University of Central Florida Libraries http://library.ucf.edu

This Article is brought to you for free and open access by the Faculty Bibliography at STARS. It has been accepted for inclusion in Faculty Bibliography 2000 s by an authorized administrator of STARS. For more information, please contactSTARS@ucf.edu.

\section{Recommended Citation}

Cho, Hyoung J. and Ahn, Chong H., "Microscale resin-bonded permanent magnets for magnetic microelectro-mechanical systems applications" (2003). Faculty Bibliography 2000s. 3673.

https://stars.library.ucf.edu/facultybib2000/3673

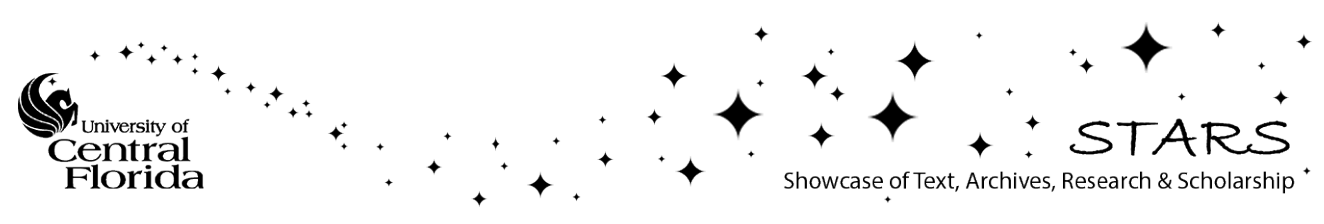




\section{Microscale resin-bonded permanent magnets for magnetic micro-electro- mechanical systems applications}

Cite as: Journal of Applied Physics 93, 8674 (2003); https://doi.org/10.1063/1.1558591

Published Online: 09 May 2003

Hyoung J. Cho, and Chong H. Ahn

\section{ARTICLES YOU MAY BE INTERESTED IN}

Wax-bonded NdFeB micromagnets for microelectromechanical systems applications Journal of Applied Physics 103, $07 E 109$ (2008); https://doi.org/10.1063/1.2830532

Bonded permanent magnets: Current status and future opportunities (invited) Journal of Applied Physics 81, 4816 (1997); https://doi.org/10.1063/1.365471

Current status and future outlook for bonded neodymium permanent magnets (invited) Journal of Applied Physics 81, 4804 (1997); https://doi.org/10.1063/1.365469

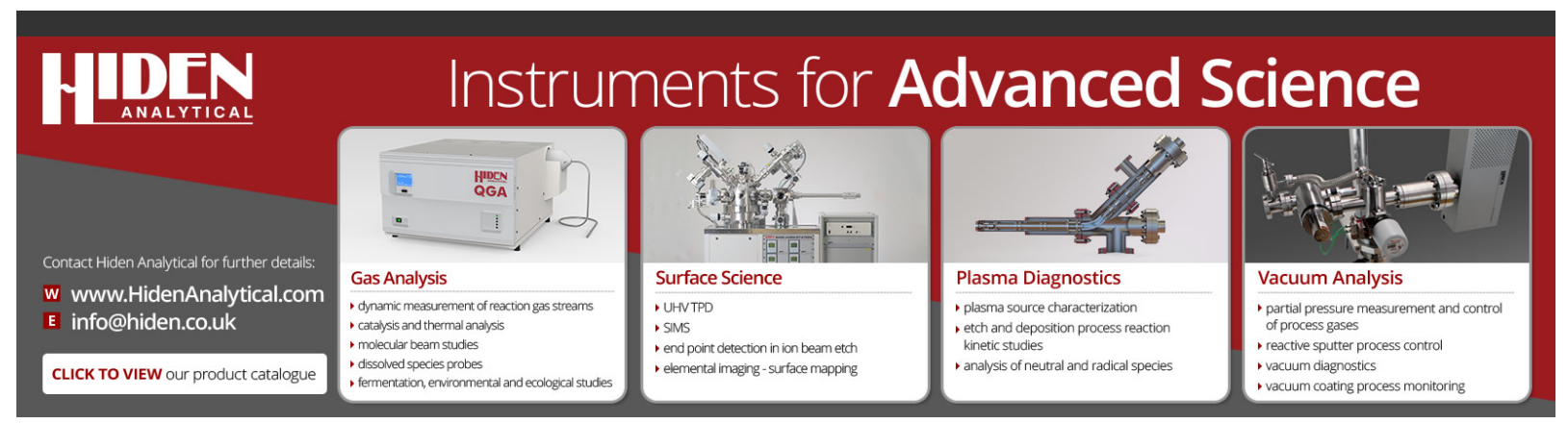




\title{
Microscale resin-bonded permanent magnets for magnetic micro-electro-mechanical systems applications
}

\author{
Hyoung J. Cho a) \\ Department of Mechanical, Materials and Aerospace Engineering, University of Central Florida, \\ P.O. Box 162450, Orlando, Florida 32816-2450 \\ Chong H. Ahn \\ Microsystems and BioMEMS Laboratory, Department of Electrical and Computer Engineering and \\ Computer Science, University of Cincinnati, P.O. Box 210030, Cincinnati, Ohio 45221-0030
}

(Presented on 15 November 2002)

\begin{abstract}
A micromachining technique has been developed for the fabrication of microscale resin-bonded permanent magnets. Magnetic paste has been prepared from Sr-ferrite powder and an epoxy resin, filled into lithographically defined molds, and formed into resin-bonded magnets after room temperature curing. Coercivity of $356 \mathrm{kA} / \mathrm{m}$ (4480 Oe), retentivity of $33 \mathrm{mT}(330 \mathrm{G})$, and energy density of $2.7 \mathrm{~kJ} / \mathrm{m}^{3}$ have been achieved in $65-\mu \mathrm{m}$-thick disk arrays with lateral dimensions ranging from 50 to $200 \mu \mathrm{m}$. Based on the developed magnet, a magnetic MEMS actuator has been designed, fabricated, and characterized. Actuation current up to $\pm 60 \mathrm{~mA}$ operated the actuator up to $70 \mu \mathrm{m}$ in attractive and repulsive motion. This work can be used for producing thick-film type permanent magnets, which can be scaled from a few tens of micrometers to millimeters on various substrates.

(C) 2003 American Institute of Physics. [DOI: 10.1063/1.1558591]
\end{abstract}

\section{INTRODUCTION}

Since the first resin-bonded magnet was demonstrated with Alnico powders and phenolic resin in 1934 by Baermann, resin-bonded magnets have been applied in various fields, especially for electromechanical devices. ${ }^{1}$ Common procedures consist of mixing and forming. First, magnetic powder and an organic binder are mixed together. Then, magnets are formed by compression, injection, or extrusion molding. Much effort has been made on making complicated shapes with precise dimension. ${ }^{2}$ Although some approaches allowed making magnets on the millimeter scale on a substrate, ${ }^{3,4}$ it is still very difficult to fabricate microscale resin-bonded magnets on a substrate. As the miniaturization of magnetic devices progresses, there is a growing demand for resin-bonded permanent magnets on the microscale. The permanent magnets can achieve relatively high energy density in microdevices, compared to other actuators with the same scale, and thus can generate long-range force with low power consumption. ${ }^{5}$ For example, a stable long-range actuator can be made and used for optical switches and scanners, which are essential components for optical communication and image processing. However, technical challenges remain in the fabrication of miniaturized magnets on the substrate for MEMS applications, which require precise control of alignment and dimension. In our previous work, a photoresist mold has been used for a relatively large conductive polymer bump structure. ${ }^{6}$ In this work, we have designed, fabricated, and characterized thick-film type resin-bonded permanent magnets with an improved aspect ratio in small dimension. Using the developed magnets, a bidirectional microactuator was designed, fabricated, and characterized.

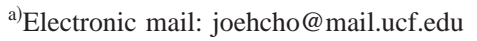

\section{MAGNET DESIGN AND FABRICATION}

For the selection of magnetic particles, preference was given to the small size of the particles. Although the rare earth magnet powder such as $\mathrm{Nd}-\mathrm{Fe}-\mathrm{B}$ or $\mathrm{Sm}-\mathrm{Co}$ based alloy is commercially available, its size is more than $10 \mu \mathrm{m}$ in a very irregular shape, which is not suitable for the application in micron scale. In comparison, Ba-ferrite $\left(\mathrm{BaFe}_{12} \mathrm{O}_{19}\right)$ or Sr-ferrite $\left(\mathrm{SrFe}_{12} \mathrm{O}_{19}\right)$ with a particle size around $1 \mu \mathrm{m}$ is easily available and shows reasonably good magnetic properties, generally, retentivity of 100-400 mT (1-4 kG), coercivity of 160-400 A/m (2000-5000 Oe), and Curie temperature of around $450{ }^{\circ} \mathrm{C} .^{7}$ Another advantage lies in their high resistivity and resulting low eddy current loss, which makes it useful in dynamic applications such as electrical motors. High coercivity, chemical stability, and low cost make ferrite magnets useful for various MEMS device applications.

In designing, the diameter of a disk was set at 50, 100, 150 , or $200 \mu \mathrm{m}$. The height was determined by the thickness of the photoresist mold and was set between 60 and $70 \mu \mathrm{m}$. Figure 1 shows the schematic view of disk arrays.

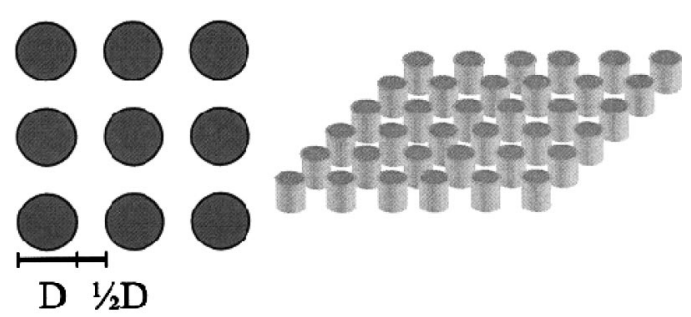

(a)

(b)

FIG. 1. Illustration of disk magnet array design: (a) top view, where $D$ $=50,100,150$, and $200 \mu \mathrm{m}$ and (b) three dimensional view of a disk array. 


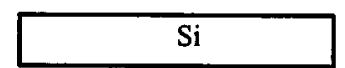

(a)

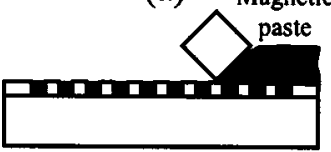

(c)

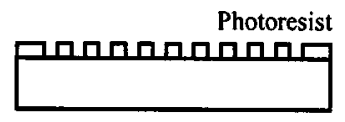

(b)

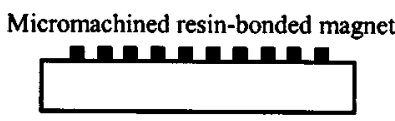

(d)
FIG. 2. Fabrication steps for miroscale resin-bonded permanent magnets: (a) substrate preparation; (b) photoresist mold patterning; (c) mold filling; and (d) photoresist removal.

For fabrication, after a silicon wafer was base-cleaned, AZ PLP-100 photoresist was spun on the wafer and patterned to build the deep molds for resin-bonded magnets. Then, magnetic paste was filled into the molds on the substrate by a rubber or a metal squeezer. The extra portion of the paste was removed with the squeezer and methanol before full curing. Figure 2 schematically describes the process for micromachining of the magnets. The magnets were then fully cured at room temperature for $24 \mathrm{~h}$. Paste residues were removed with oxygen reactive ion etching (RIE). Due to the difference in chemical resistance between the photoresist and fully cured magnetic paste, the photoresist molds could be removed with acetone, leaving behind the permanent magnet array patterns on the substrate.

Separate from the mold fabrication, magnetic paste was prepared from commercial grade Sr-ferrite powder (Fermag Technologies, Inc.) and room temperature curable epoxy resin (Devcon). The typical formulation was 45 vol \% of magnetic particles in the paste. Figure 3 shows a typical shape of the magnet in disk array form.

\section{CHARACTERIZATION}

Micromachined permanent magnets were magnetically characterized with a vibrating sample magnetometer (VSM). A typical demagnetization hysteresis loop is shown in Fig. 4. Although there was variation in magnetic properties from one disk array to another, different samples from the same magnetic paste batch did not show much difference in char-

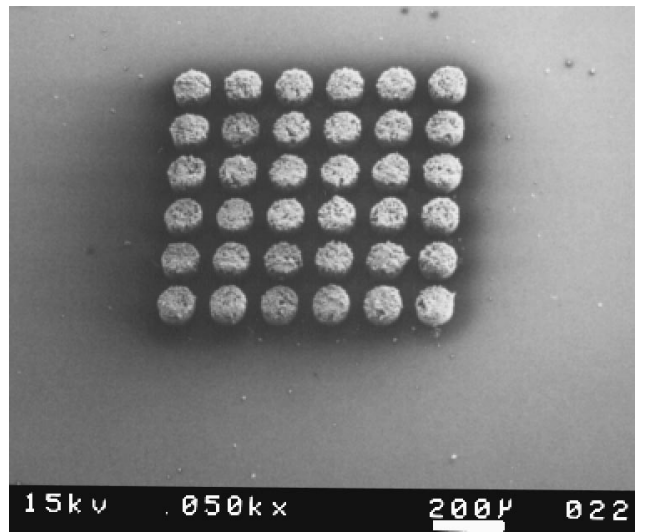

FIG. 3. Resin-bonded magnet disk array fabricated by a micromachining technique. Shown is a $6 \times 6$ array of $100 \mu \mathrm{m}$ diameter disk magnets.

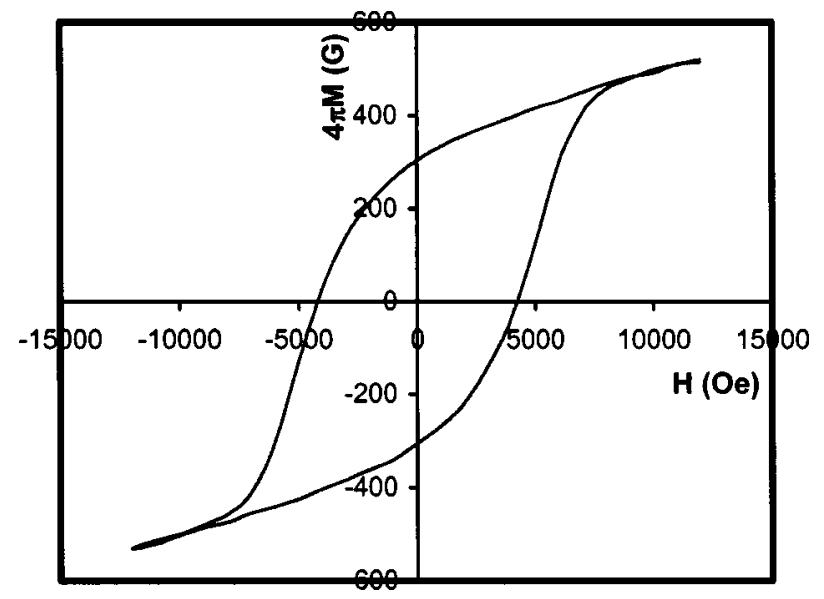

FIG. 4. A typical $4 \pi M-H$ hysteresis loop of the resin-bonded disk magnet.

acteristics. Rather, any small variation could be from the defects such as resin filled gaps and pores that generate a demagnetization field in a magnet. The measured magnetic properties are almost uniform regardless of diameter. Stored magnetic energy in a single disk is only dependent on the volume, thus proportional to the square of the radius, as shown in Fig. 5. Magnetic properties are summarized in Table I.

\section{APPLICATION}

Using the developed magnet, a magnetic microactuator was designed, fabricated, and characterized. A silicon wafer was chemically etched in $\mathrm{KOH}$ solution to form around 20$\mu$ m-thick silicon membrane. Then, a resin-bonded magnet was fabricated on the membrane. The silicon membrane was dry-etched with RIE from the flat side, leaving behind the serpentine torsion beam. Finally, a torsion bar type magnetic microactuator carrying resin-bonded magnets was completed after assembly of a spacer and an electromagnet. Figure 6 shows one example of the integrated magnets in the silicon

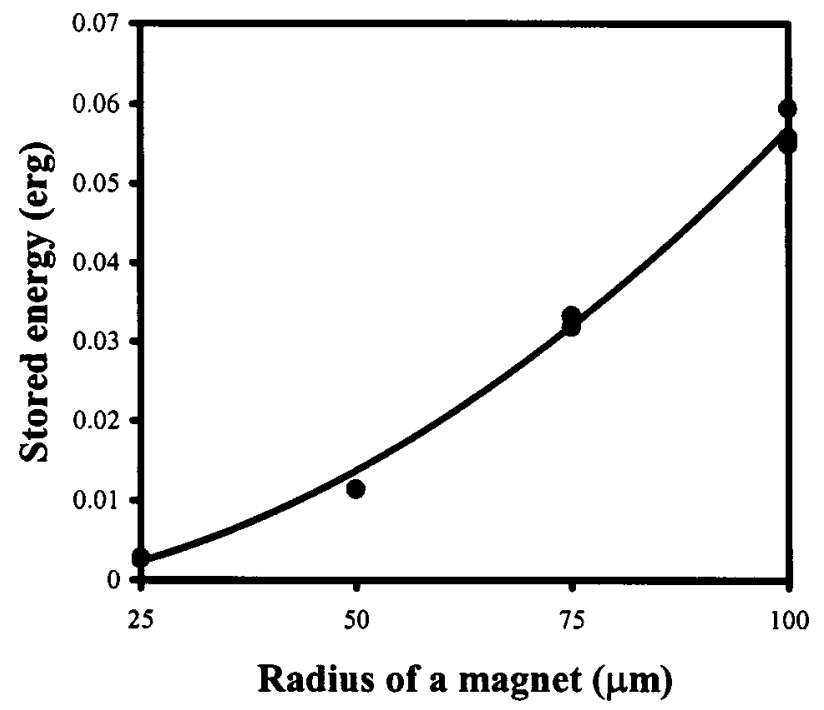

FIG. 5. Stored magnetic energy in a disk magnet as a function of dimension. 
TABLE I. Magnetic properties of micromachined magnets.

\begin{tabular}{ll}
\hline \hline Coercivity, $H_{c}$ & $4450-4480 \mathrm{Oe}$ \\
Retentivity, $4 \pi M_{r}$ & $300-330 \mathrm{G}$ \\
Energy density, $(B \cdot H)_{\max }$ & $2.1-2.7 \mathrm{~kJ} / \mathrm{m}^{3}$ \\
\hline
\end{tabular}

microactuator. Deflection was measured with a laser displacement sensor (Keyence LC 2400, 2420) while applying electrical current to the actuator with a power supply (HP 6825A). A serpentine torsion beam type actuator showed up to $\pm 70 \mu \mathrm{m}$ deflection bidirectionally with actuation currents of $\pm 60 \mathrm{~mA}$ under a static operation condition. The static characteristic of the actuator is shown in Fig. 7. It is obvious that the actuator generates attractive and repulsive motion due to the permanent magnet on the moving silicon structure.

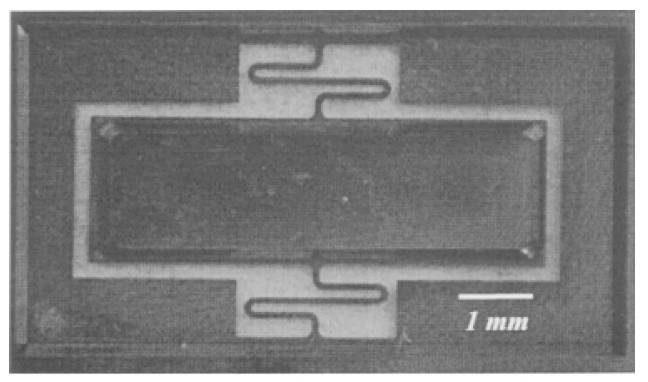

(a)

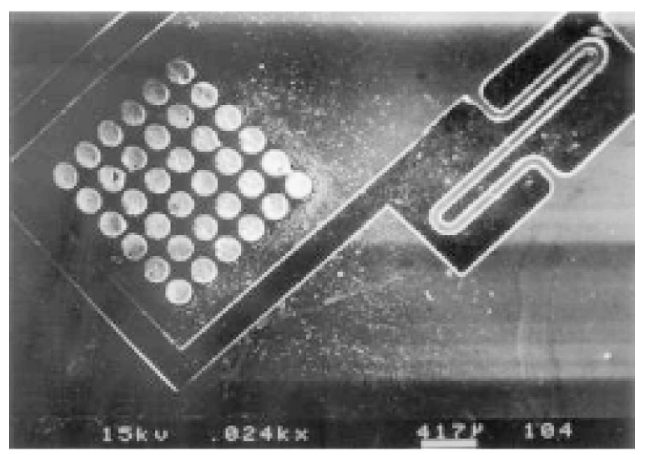

(b)

FIG. 6. A torsion bar type magnetic microactuator with integrated resinbonded magnets: (a) top view and (b) bottom view.

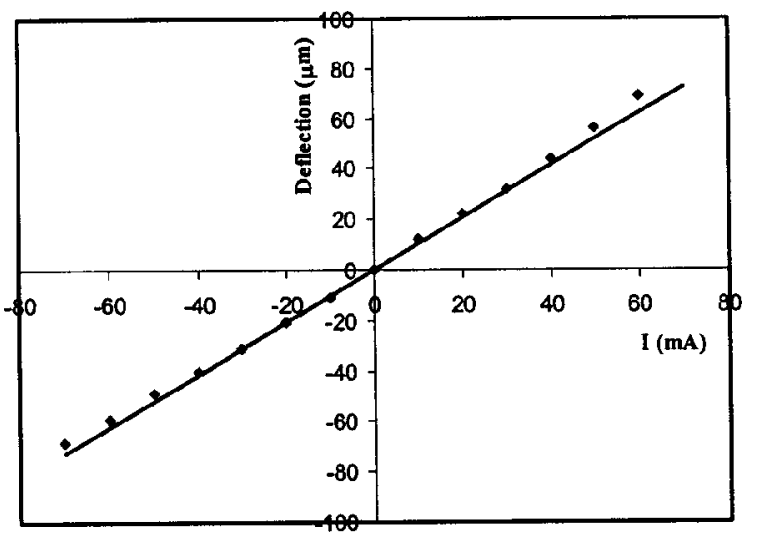

FIG. 7. Static deflection of the microactuator in attractive $(-)$ and repulsive $(+)$ motion as a function of the actuation current.

\section{CONCLUSION}

In this work, resin-bonded permanent magnets have been fabricated in the microscale and applied to a magnetic MEMS actuator. Lithographically defined thick photoresist molds have been used for precisely controlled shape. Coercivity of $356 \mathrm{kA} / \mathrm{m}$ (4480 Oe), retentivity of $33 \mathrm{mT}$ (330 G), and energy density of $2.7 \mathrm{~kJ} / \mathrm{m}^{3}$ have been achieved in a 65 - $\mu \mathrm{m}$-thick disk-type magnet with lateral dimensions ranging from 50 to $200 \mu \mathrm{m}$. A magnetic actuator fabricated on silicon substrate has shown capability and compatibility of micromachined magnets for MEMS applications. Bidirectional deflection as large as $70 \mu \mathrm{m}$ has been observed. The developed magnet and the micromachining technique can be used for various devices requiring small magnets.

\section{ACKNOWLEDGMENTS}

The authors appreciate Dr. Dong-Seon Lee at the University of Cincinnati and Dr. Soon-Cheon Byeon at the University of Alabama for technical assistance in characterization.

${ }^{1}$ H. R. Kirchmayr, J. Phys. D 29, 2763 (1996).

${ }^{2}$ M. Hamano, J. Alloys Compd. 222, 8 (2001).

${ }^{3}$ L. K. Lagorce, O. Brand, and M. G. Allen, J. Microelectromech. Syst. 8, 2 (1999).

${ }^{4}$ B. M. Dutoit, P.-A. Besse, H. Blanchard, L. Guerin, and R. S. Popovic, Sens. Actuators 77, 178 (1999).

${ }^{5}$ J. W. Judy, Smart Mater. Struct. 10, 1115 (2001).

${ }^{6}$ K. W. Oh and C. H. Ahn, IEEE Trans. Adv. Packag. 22, 586 (1999).

${ }^{7}$ R. A. McCurrie, Ferromagnetic Materials Structure and Properties (Academic, London, 1994). 